\title{
Deteksi Keausan Alat pada Proses Pengeboran Sumber Alam
}

\author{
Siana Halim ${ }^{*}$, Felecia ${ }^{1}$
}

\begin{abstract}
In this paper we applied change point detection methods for failures detection in the drilling process. We calculated the change points on three drilling parameters, i.e., the weight on bit, top drive torque and rate of penetration. Using the concept of reliability, we measured the time between change points as the time between failures. The minimum of mean time between change points from those three parameters is suggested to be the time for monitoring the drilling process.
\end{abstract}

Keywords: Change point detection, drilling, mean time between failures.

\section{Pendahuluan}

Dalam industri pengeboran minyak ataupun sumber daya alam yang lain, proses monitoring merupakan hal krusial yang harus dilakukan. Biaya yang sangat mahal dan teknologi kompleks yang berada pada industri ini membutuhkan proses monitoring yang handal sehingga deteksi keausan alat, seperti mata bor (bit) dapat diketahui sedini mungkin.

Berbagai metode telah dikembangkan untuk menjawab tantangan di atas. Messaoud dan Weihs [9] menggunakan nonlinear time series untuk memonitor proses pengeboran. Secara umum Messaoud [8] meneliti tentang penggunaan statistical process control dalam proses pengeboran. Theis [10] memodelkan amplitude dari getaran yang ditimbulkan saat pengoboran dengan time series analysis dan stochastic differential equation.

Secara mekanikal monitoring proses pengeboran dapat dilakukakan dengan konsep Mechanical Specific Energy. Pada konsep ini perbandingan antara input energy terhadap output energy pada saat pengeboran dimonitor (Dupriest dan Koederitz [2], Kumar [7]).

Pada makalah ini, monitoring pada proses pengeboran dilakukan dengan pendekatan change point pada parameter-parameter yang diperhatikan pada proses pengeboran. Waktu untuk memonitor proses pengeboran ini ditentukan dengan menggunakan minimum mean time between change points dari parameter-parameter yang digunakan pada proses pengeboran. Mean time between change points ini dapat dianggap sebagai mean time between failures pada konsep keandalan.

\footnotetext{
1 Fakultas Teknologi Industri, Program Studi Teknik Industri, Universitas Kristen Petra, Jl. Siwalankerto 121-131, Surabaya 60238. Email: halim@peter.petra.ac.id

* Penulis korespondensi
}

\section{Metode Penelitian}

\section{Parameter Pengeboran}

Terdapat banyak parameter yang harus diperhatikan pada proses pengeboran (Gambar 1). Dalam makalah ini hanya akan dipilih tiga parameter saja yaitu Weight on Bit (WOB), Top Drive Torque (TDR) dan Rate of Penetration (ROP). Pada uji dependensi, ketiga parameter dapat digunakan untuk mewakili proses monitoring pada proses pengeboran. Tentunya hal ini masih dapat dikembangkan untuk penelitian selanjutnya.

WOB merupakan jumlah gaya ke bawah yang ditempatkan pada bit(mata bor). TDR merupakan gaya balik (turning force) yang diterapkan pada poros atau mekanisme lain yang berputar ataupun cenderung berputar. Hal umum yang perlu diketahui adalah beban axial (lebih dikenal dengan WOB) dan torque merupakan parameter yang sangat penting pada proses pengeboran. Keduanya mempengaruhi arah dan kemiringan bor serta ekonomi dari proses pengeboran tersebut. TDR sangat dipengaruhi oleh rotation per minute (RPM) yang dipilih dan juga dipengaruhi oleh desain dari Bottom Hole Assembly (BHA).

ROP adalah kecepatan proses pengeboran yang dicatat per menit. Tujuan (Objective) dari strategi pengeboran adalah memaksimumkan ROP dan memaksimumkan lifetime dari mata bor (drilling bit).

\section{Change Point}

Terjadi kerusakan/keausan pada proses pengeboran ini dapat dideteksi dengan adanya data yang out of control. Salah satu cara untuk meminimumkan terjadinya out of control adalah dengan mendeteksi titik dimana mulai terjadi pergeseran data menuju out of control (Zou et al. [11]). Pergeseran tersebut dikenal dengan change point (lihat Gambar 2). 


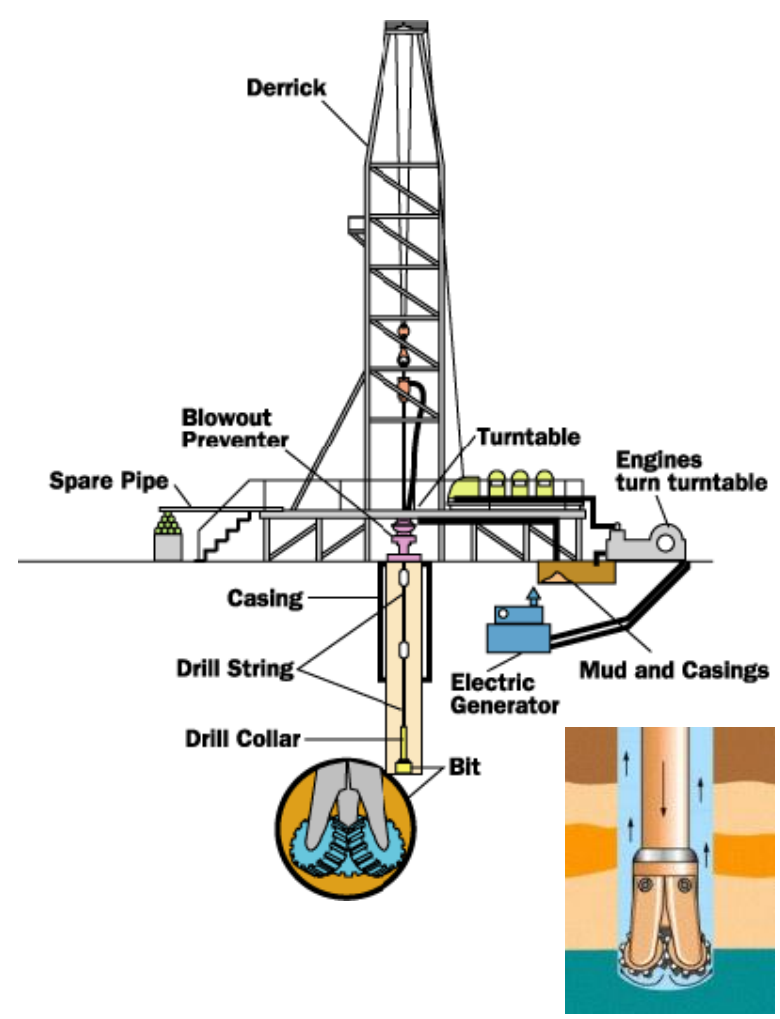

Gambar 1. Proses pengeboran

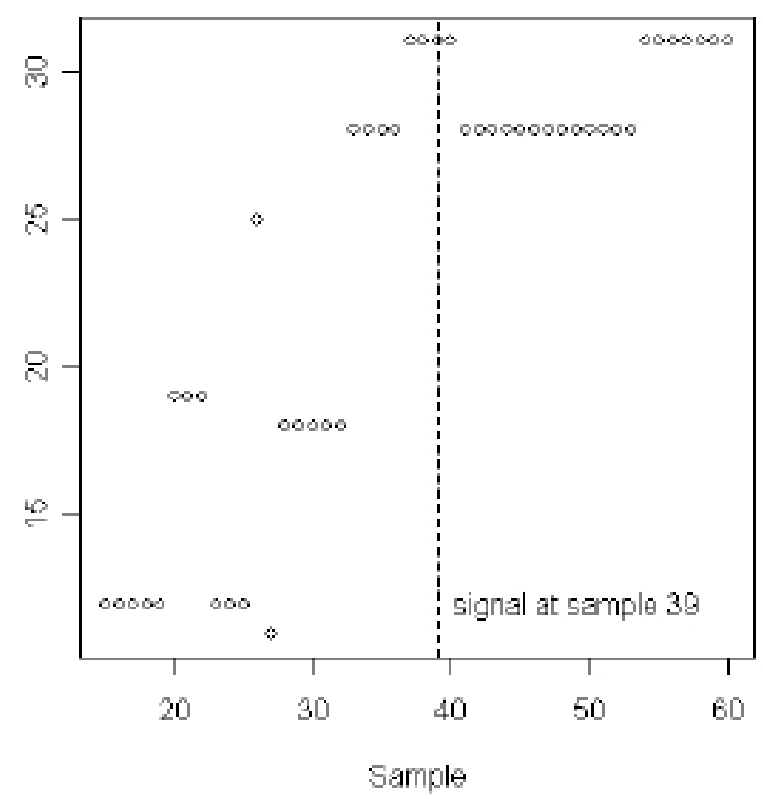

Gambar 2. Change Point pada Control Chart (Deng, 2009)

\section{Model Change Point}

Ada dua pendekatan change point yang dapat digunakan, yaitu secara parametrik dan nonparametrik. Beberapa model parameterik klasik yang sering digunakan adalah Cumulative Sum (CUSUM) dan Exponentially Weighted Moving Average (EWMA). Pada pendekatan parameterik, seringkali asumsi yang digunakan dalam membangun model tersebut adalah data yang ber- distribusi normal. Namun, pada kenyataannya, seringkali distribusi dari suatu proses terkadang tidak berdistribusi normal ataupun tidak diketahui. Deng ([1]), memberikan beberapa model penentuaan change point, antara lain CUSUM control chart dengan pendekatan Wilcoxon Signed Rank (WSR), control chart dengan pendekatan Group Signed Rank (GSR) statistic dan control chart GSR-EMWA. Selain itu, Hawkins et al. [3] mengembangkan parametric change point HQK model. Model ini menggunakan pendekatan CUSUM dan GSR.Model ini dilanjutkan oleh Hawkins dan Zamba ([4] dan [5]) dengan memperhatikan pergeseran mean dan variance.

Hawkins dan Deng [6] mengembangkan model nonparametrik change point untuk mengatasi kelemahan pada pendekatan parameterik. Pada pendekatan ini Hawkins dan Deng menggunakan pendekatan Mann-Whitney. Secara umum model tersebut dapat dituliskan sebagai berikut:

$X_{i} \sim F(x), i=1,2,3, \ldots, \tau$

$X \sim F(x+\theta), i=\tau+1, \tau+2, \tau+3, \ldots, n$

dimana $\tau$ adalah posisi terjadinya change point dalam fix-sample. Hipotesa pergeseran data dapat diformulasikan sebagai $H_{0}: \theta=0$ vs $H_{1}: \theta \neq 0$.

Uji dua sample dari $U$ - Statistik dari Mann-Whitney yang digunakan sebagai dasar pembentukan change point dituliskan sebagai

$U_{k, n}=\sum_{i=1}^{k} \sum_{j=k+1}^{n} D_{i j}, \quad 1 \leq k \leq n-1$

dimana

$$
\begin{aligned}
D_{i j}= & \operatorname{sgn}\left(X_{i}-X_{j}\right) \\
& =\left\{\begin{array}{c}
1 \text { jika } X_{i}>X_{j} \\
0 \text { jika } X_{i}=X_{j} \\
-1 j i k a X_{i}<X_{j}
\end{array}\right.
\end{aligned}
$$

Seringkali $U$ - Statistik dihitung dengan menggunakan pendekatan ranking dari populasi data $\left(R_{i}\right)$. Hal ini dilakukan untuk mempermudah komputasi.

$U_{k, n}=2 \sum_{i=1}^{k} R_{i}-k(n+1)$

Deteksi change point dapat dilakukan dengan mengukur nilai $T$ - Statistik

$T_{k, n}=\frac{U_{k, n}}{\sqrt{k(n-k)(n+1) / 3}}$

Posisi terjadinya change point dapat ditentukan melalui maksimum $T$-statistik pada seluruh $k$

$T_{\max , n}=\max _{1 \leq k \leq n}\left|T_{k, n}\right|$ 
Jika $T_{k, n}$ maksimum lebih besar dari batas control chart yang telah ditentukan, yaitu $h_{\alpha, n}$ maka pada titik tersebut terjadi change point (lihat HawkinsDeng [6]).

\section{Hasil dan Pembahasan}

Beberapa masalah sering terjadi pada saat proses pengeboran, diantaranya adalah torque yang terlalu tinggi, problem pada pompa, bit mencapai dasar, problem pada hidrolik, dan sebagainya.

Tiga parameter yang akan diuji pada makalah ini dicatat setiap menit dan setiap masalah yang menyebabkan proses pengeboran berhenti juga dicatat pada data tersebut. Hal ini dimungkinkan karena pada proses pengeboran monitoring dilakukan secara terus menerus.

Konsep yang digunakan dalam penentuan change point adalah dengan membandingkan rata-rata sebelum dan rata-rata setelah terjadinya change point. Hipotesa yang digunakan dalam penentuan posisi change point adalah sebagai berikut:

$\mathrm{H}_{0}$ : Rata-rata data sebelum dan setelah change point adalah sama

$\mathrm{H}_{1}$ : Rata-rata data sebelum dan setelah change point adalah tidak sama

Hawkins-Deng [6] menggunakan konsep dari MannWhitney yang menggunakan $T$-statistik dari sudent$t$ statistik sebagai dasar penolakan atau penerimaan hipotesa. Change point ditentukan dengan membandingkan $T$-statistik dengan limit $\left(h_{\alpha, n}\right)$. Posisi change point dilihat dari nilai $T$-statistik yang paling dekat dengan nilai limit yang diperoleh dari tabel Hawkins-Deng [6]. Nilai limit ini dipengaruhi oleh tiga hal yaitu tingkat signifikansi, derajat kebebasan dan tipe pengujian (satu arah ataupun dua arah). Pada kasus pengeboran ini digunakan tingkat signifikan sebesar $1 \%(\alpha=0.01)$. Derajat kebebasan ditentukan berdasarkan jumlah warm up data yang digunakan. Pada kasus ini warm up data yang digunakan adalah 14 data, sehingga nilai derajat kebebasannya adalah 13. Jenis pengujian yang digunakan adalah pengujian dua arah. Berdasarkan tiga hal tersebut, nilai limit dalam proses pengeboran ini adalah 3.

Change point didapatkan dari simulasi yang dilakukan dengan menggunakan software R. Simulasi dilakukan pada ketiga parameter yang ada, yaitu WOB, TDR, dan ROP dengan masing-masing menggunakan 1877 data, pada waktu tertentu data tersebut ditandai dengan catatan tentang kerusakan yang terjadi pada saat itu.
Pengujian dimulai dari data ke-15 (empat belas data digunakan sebagai warm-up). Pada blok data pertama ini $(n=15)$ dilakukan perhitungan $T$ Statistik pada persamaan (5), untuk $k=1, \ldots, 15$. Nilai $T$-Statistik ini dibandingkan dengan limit yang telah ditentukan yaitu 3. Selanjutnya, nilai $n$ ditingkatkan satu persatu, dan pengujian $T$-Statistik dilakukan untuk nilai $k$ yang bersesuaian. Pengujian ini dihentikan sebelum data kerusakan yang sesungguhnya terjadi, dan seluruh nilai change point yang terjadi pada periode tersebut dicatat. Tabel 1 memberikan gambaran tentang prosedur perhitungan $T$-statistik pada 1 periode kerusakan. Pada periode pertama ini kerusakan terjadi pada menit ke-172. Change point pertama yang terjadi pada WOB terdeteksi pada data ke-11 atau 161 menit sebelum kerusakan yang sebenarnya terjadi, sedangkan pada TDR adalah pada data ke-14 atau 158 menit sebelum kerusakan yang sebenarnya terjadi dan pada ROP adalah pada data ke-26 atau 146 menit sebelum kerusakan pertama terjadi.

Pada Tabel 1 terlihat bahwa WOB memberikan sinyal change point paling banyak bila dibandingkan dengan TDR dan ROP, WOB juga memberikan sinyal terdekat, yaitu 1 menit sebelum kerusakan terjadi. Proses perhitungan ini berulang untuk setiap periode kerusakan yang tercatat pada data.

Plot T-statistik terhadap indeks sinyal dan nilai limit untuk WOB, TDR dan ROP, masing-masing dapat dilihat pada Gambar 3 - Gambar 5. Pada Gambar 3 terlihat bahwa terdapat titik yang telah melebihi batas yang telah ditentukan. Hal ini mengindikasikan bahwa telah terjadi change point pada saat itu.

Simulasi untuk mencari titik change point ini dilakukan pada seluruh data yang ada dari ketiga parameter. Terdapat 75 titik change point pada data WOB, 47 titik change point pada data TDR, dan 80 titik change point pada data ROP. Data TDR memiliki titik change point yang lebih sedikit karena data pada parameter ini lebih halus dan tidak bergejolak dibandingkan dengan parameter yang lain.

Waktu untuk memonitor proses pengeboran ditentukan dengan memperhatikan selang waktu terjadi change point pada ketiga parameter yang diamati. Pada penelitian ini digunakan konsep mean time between failure (MTBF) untuk menentukan waktu tersebut. MTBF ini ditentukan berdasarkan distribusi yang bersesuaian untuk masing-masing parameter. 
Tabel 1. Contoh hasil pendeteksian change point

\begin{tabular}{crrrrrr}
\hline Sinyal & \multicolumn{2}{c}{ WOB } & \multicolumn{2}{c}{ TDR } & \multicolumn{2}{c}{ ROP } \\
\cline { 2 - 7 } ke & Data & Menit & Data & Menit & Data & Menit \\
\hline 1 & 11 & 161 & 14 & 158 & 26 & 146 \\
2 & 22 & 150 & 37 & 135 & 48 & 124 \\
3 & 27 & 145 & 62 & 110 & 57 & 115 \\
4 & 42 & 130 & 94 & 78 & 63 & 109 \\
5 & 69 & 103 & 109 & 63 & 70 & 102 \\
6 & 87 & 85 & 121 & 51 & 79 & 93 \\
7 & 96 & 76 & & & 86 & 86 \\
8 & 111 & 61 & & & 91 & 81 \\
9 & 120 & 52 & & & 99 & 73 \\
10 & 132 & 40 & & & 169 & 3 \\
11 & 165 & 7 & & & & \\
12 & 171 & 1 & & & &
\end{tabular}

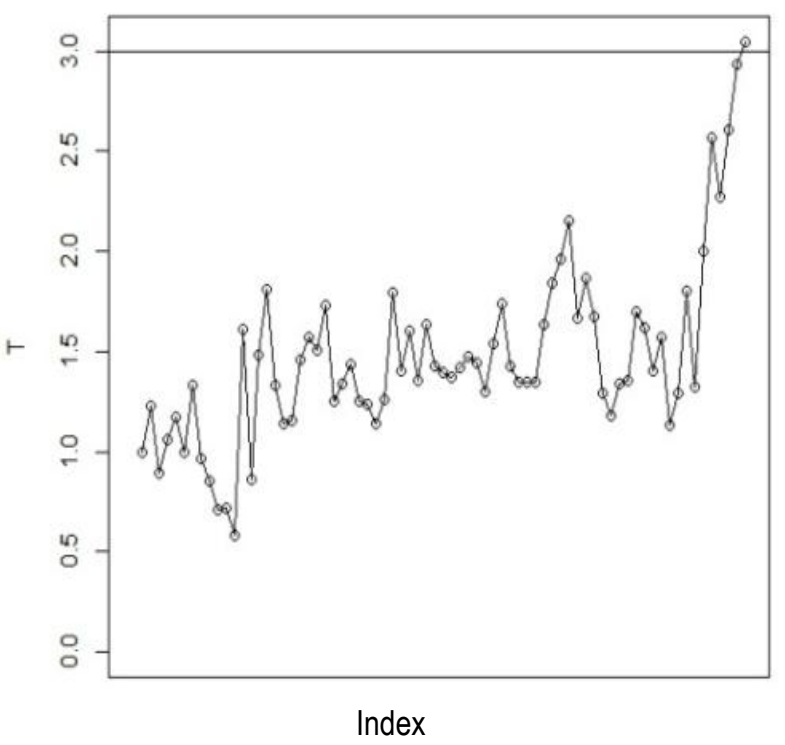

Gambar 3. Grafik output dari simulasi data WOB

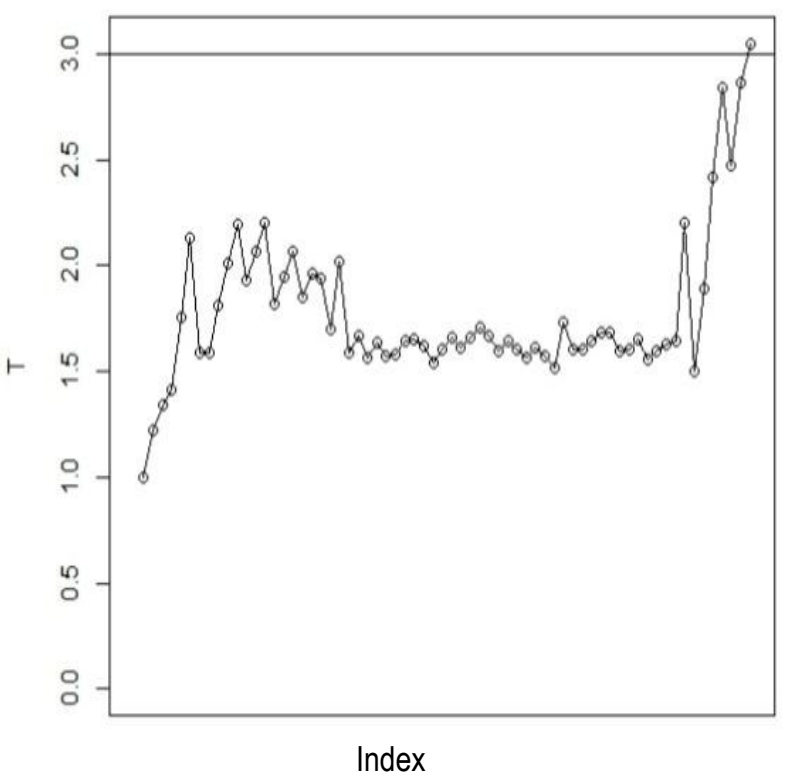

Gambar 4. Grafik output dari simulasi data TDR

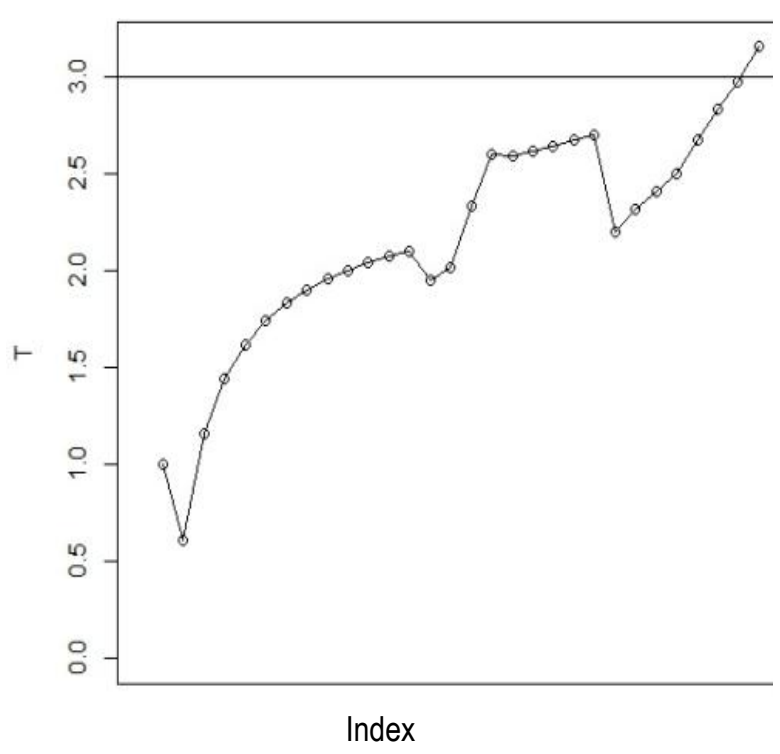

Gambar 5. Grafik output dari simulasi data ROP

Pada parameter WOB distribusi dari waktu antara change point yang terjadi sesuai (fit) dengan distribusi exponensial dengan rata-rata 52,87 menit (Gambar 6). Waktu antara change point pada TDR juga bersesuaian dengan distribusi exponensial, dengan rata-rata 56,19 menit (Gambar 7). Distribusi yang sama yaitu exponensial juga sesuai untuk mengambarkan distribusi dari waktu antara change point pada ROP, dengan nilai rata-rata 57,32 menit (Gambar 8). Nilai rata-rata terkecil inilah yang akan digunakan sebagai waktu untuk memonitor proses pengeboran. Nilai ini diberikan oleh nilai rata-rata dari waktu antara change point yang terjadi pada WOB, yaitu sebesar 52,87 menit.

Berdasarkan nilai MTBF inilah maka setiap 52 menit pemeriksaan terhadap proses pengeboran perlu dilakukan untuk mencegah terjadinya kerusakan pada proses tersebut.

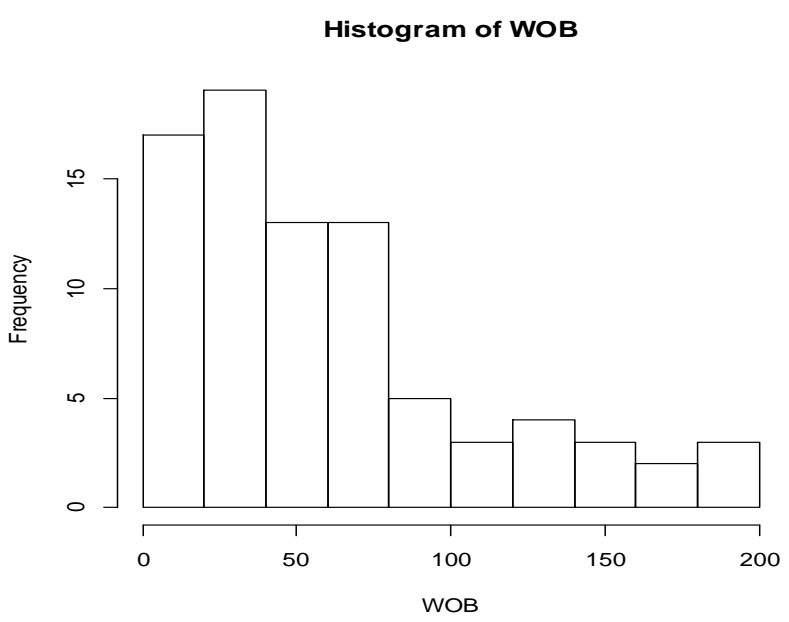

Gambar 6. Distribusi change point yang terdeteksi pada data WOB 


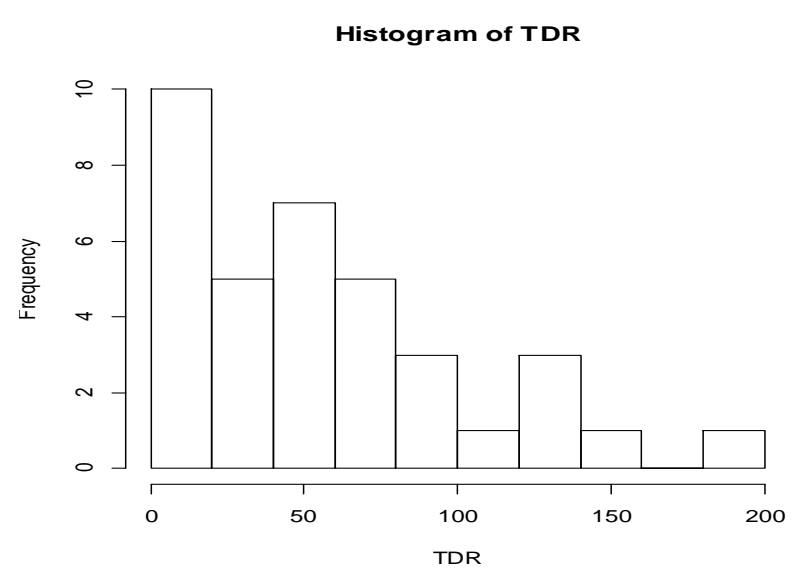

Gambar 7. Distribusi change point yang terdeteksi pada data TDR

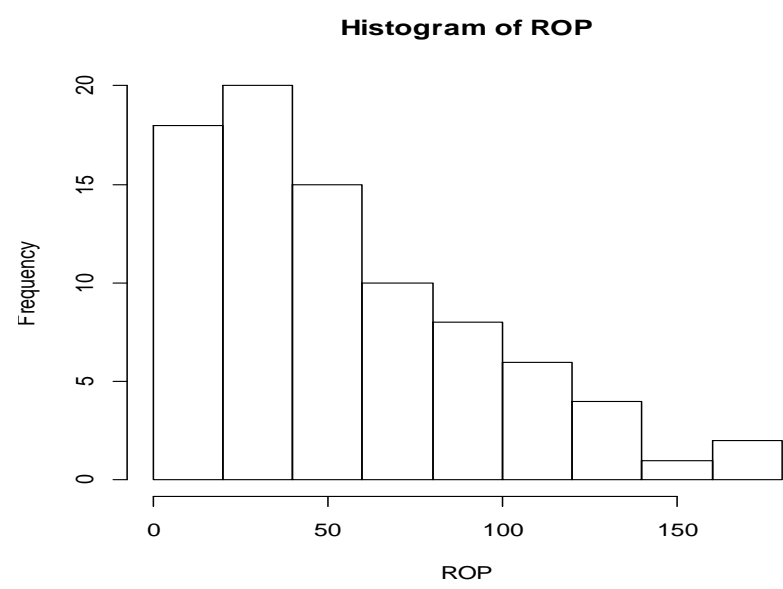

Gambar 8. Distribusi change point yang terdeteksi pada data ROP

\section{Simpulan}

Metode non-parametric change point dapat digunakan untuk mendeteksi lebih awal kerusakan atau keausan pada proses pengeboran. Informasi change point pada tiga parameter yang diamati, juga akan digunakan sebagai dasar penentuan selang waktu pemeriksanaan untuk mencegah terjadinya kerusakan pada proses pengeboran. Pada kasus ini proses pemeriksaan yang perlu dilakukan adalah setiap 52 menit sekali.

Penelitian ini masih dapat dilanjutkan dengan membangun model untuk mendeteksi kerusakan pada alat-alat pengeboran secara real time.

\section{Ucapan Terima Kasih}

Penulis mengucapkan terima kasih kepada saudara Genesius Chandra yang telah membantu menjalankan simulasi pada program $R$.

\section{Daftar Pustaka}

1. Deng, Q., A Nonparametric Change Point Model for Phase II Analysis, Thesis, University of Minnesota, 2009.

2. Dupriest, F. E., and Koederitz, W. L., Maximizing Drill Rates with Real Time of Surveillaince of Mechanic Spesific Energy, Proceeding of International Association of Drilling Contractors SPE/IADC Drilling Conference, Amsterdam, 2325 February, 2005.

3. Hawkins, D. M., Qiu, P., and Kang, C. W., The Change Point Model for Statistical Process Control, Journal of Quality Technology, 35(4), 2003, pp. 355-366.

4. Hawkins, D. M., and Zamba, K. D., A Change Point Model for a Shift in Variance, Journal of Quality Technology, 37(1), 2005, pp. 21-31.

5. Hawkins, D. M., and Zamba, K. D., Statistical Process Control for Shifts in Mean or Variance Using a Change Point Formulation, Technometric, 47(2), 2005, pp. 164-173.

6. Hawkins, D. M., and Deng, Q., A Nonparametrik Change Point Control Chart, Journal of Quality Technology, 42(2), 2010, pp. 165-173.

7. Kumar, A. S., A Baseline for Mechanical Spesific Energy and Estimation of Bit Wear Rate, Thesis, University of Texas Austin, 2008.

8. Messaoud, A. B. S., Monitoring Strategies for Chattering Detection in a Drilling Process, Doctoral Thesis, University of Dortmund, 2006.

9. Messaoud, A. B. S., and Weihs, C., Monitoring a Deep Hole Drilling Process by Nonlinear Time Series Modelling, Journal of Sound and Vibration, 321, 2009, pp. 620-630.

10. Theis, W., Modeling Varying Amplitude, Doctoral Thesis, University of Dortmund, 2003.

11. Zhou, C., Zhou, C., Zhang, Y., and Wang, Z., Nonparameteric Control Chart based on Change-point Model, Statistical Paper, 50(1), 2009, pp. 13-28. 